\title{
Quality of Production Process With CAD/CAM SYSTEM SUPPORT
}

\author{
JAMBOR, J.
}

Abstract: This publication deals about the simulation process and CNC program generation in the system CATIAV5. In this high class of CAD/CAM system is possible to manufacture models with too complicated shapes and CNC code then finally transfer into the operating systems of CNC machining centers. Each machining technology must be supported by selection of the relevant cutting tools and cutting materials, design and use of plant and machinery suitable for innovative machining technology, which benefits must always be continuous reduction in production time and mechanical machining time in each operation, subject to the quality and accuracy of the product. Production processes have to be optimized by CAD/CAM systems application in the technological preparation of production and use of innovation in programming CNC machine tools.

Key words: CAD/CAM system, computer aided manufacturing, quality process, CNC programming, postprocessor
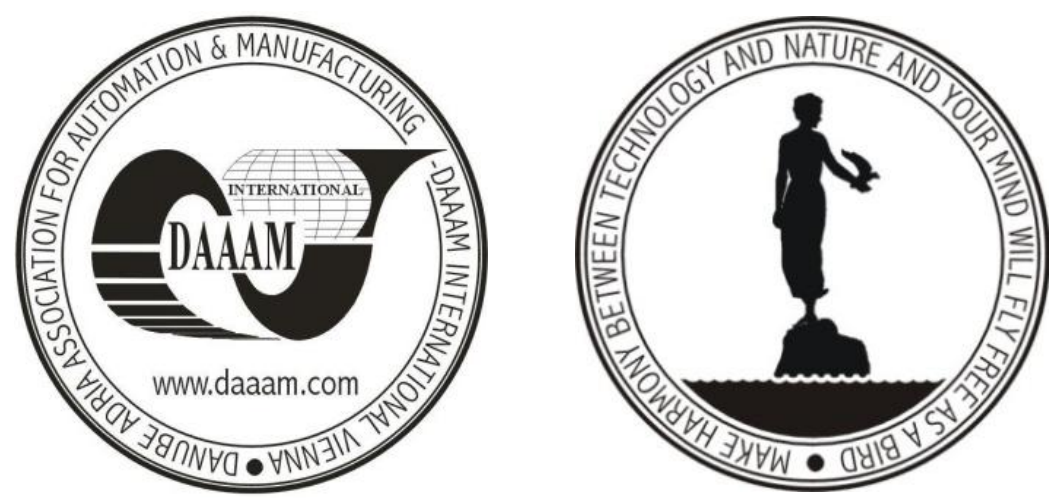

Authors' data: Dipl.-Ing. PhD. Jambor, J[aroslav]; Dubnica Institute of Technology DTI, Sladkovicova 533/20, 01841 Dubnica nad Vahom, Slovakia, jambor.jaroslav@gmail.com

This Publication has to be referred as: Jambor, J[aroslav] (2012). Quality of Production Process with CAD/CAM System Support, Chapter 24 in DAAAM International Scientific Book 2012, pp. 277-286, B. Katalinic (Ed.), Published by DAAAM International, ISBN 978-3-901509-86-5, ISSN 1726-9687, Vienna, Austria DOI: $10.2507 /$ daaam.scibook.2012.24 
Jambor, J.: Quality of Production Process with CAD/CAM System Support

\section{Introduction}

Great importance to all new technologies, materials, machinery, progressive methods and information tools that enable more efficient use of starting materials, produce a more cost effective, fast enough to produce reliable and quality products and above all succeed in the market in an increasingly challenging competitive environment. Today's trend component is machining in one setup, with minimal clamping. This is achieved by the time reduction of the final machining, while eliminating inaccuracies caused by manual switching of the workpiece.

Author's research is limited to the qualitative aspects of the production process, except where the use of advanced machines and software points to the most appropriate production technology application with regard to the overall production time while maintaining the quality of the product, which are measurable as macrogeometry and microgeometry of machined surfaces and components.

Overall programming $\mathrm{CNC}$ machines is carried out at three levels:

- DIN ISO programming, which is manually inserted $\mathrm{G}$ and $\mathrm{M}$ codes. The advantage is accurate programming of each movement. The disadvantage is the error of the human factor.

- Higher workshop programming. Application with these systems required minimum knowledge of DIN ISO programming. All information about the workpiece is graphically entered, which makes operating the machine. The advantage is the possibility of simulation (Majerik \& Jambor, 2010)

- CAD/CAM systems, which are a complex preparation of production process. CAD is computer-supported design for preparation production. Capable drawings a 3 dimensional model of the product, creating technical documentation, conversion from $2 \mathrm{D}$ to $3 \mathrm{D}$ display. CAM is computer aided manufacturing. It is a kind of automation through computerization. CAM brings the possibility of simulation machine cycles. Integration of $\mathrm{CAD} / \mathrm{CAM}$ offers the possibility to generate $\mathrm{NC}$ codes of design components (Jambor \& Majerik, 2009).

Machining of various components of complex shape, using milling, drilling holes and so on, it is possible to implement more gripping and carrying out each operation machining on various machine tools. By automating the production process of such components can be performed all the operations to a minimum number of clamping in more axial CNC machining center. CAD Support/CAM system makes faster the entire production process, and what is particularly important in those parts of complex shape of scale (Majerik, Baska \& Danisova, 2009).

\section{Qualitative aspects of manufacturing process}

Increasing competitive pressure is forcing companies and firms to more intense than ever, use of technical innovation. In the area of machining exists the advanced technologies which reduce production times respectively otherwise save on overall production costs. They are the following technologies:

- High-speed machining (High Speed Cutting - HSC),

- High Performance Machining (High Power Cutting - HPC, HFC), 
- Dry Machining - DM,

- Machining with minimal lubrication (MQL, MMS),

- Machining of hardened metal materials (HM - Hard Machining)

Combined methods of machining (turning milling, plunge milling, drilling, planetary milling, thread milling circular ...) are applicable only to CNC machine tools (Majerik \&Sandora, 2012).

\subsection{Qualitative aspects of HSC machining process}

High-speed machining is applied with significantly higher cutting speeds $v_{c}$ the relatively small cross sections cut. High-speed machining technology is realized with extremely hard and heat-resistant cutting tools. Temperature in the cutting zone and chip creation approaches the melting temperature of workpiece. Chip in the transition shear plane shear increases across its cross-section of a sudden its temperature, turn red and soften hardened steel scrap and thus reduce its downforce on the front of the instrument.

Total friction force and cutting resistance decreases, when increases the angle of shear plane $\beta_{l}$, also a narrow gauge particles together at the exit from the contact zone, reducing surface contact area with the tool and reduce the secondary particles increase in temperature in the friction contact zone. Chips from the contact area moves very fast and have no time to pass heat tool or workpiece. This minimizes heat transfer into the tool and workpiece, and most of the resulting heat goes into the chips. All this despite an overall increase in heat reduce tool wear. As a result of cutting forces decreasing and reduce heat transfer into the workpiece and increases machining accuracy. Current high-speed machining applications, especially small diameter milling cutters with shank monolithic resistant coatings deliver a reduction in production times by up to $90 \%$ and reduce production costs by up to $50 \%$.

With increasing cutting speed $v_{c}$ are achieved by HSC following benefits:

- significant reduction in mechanical machining time $-t_{A S}$,

- the possibility of increasing the volume of particles of about $30 \%$,

- increase the speed chart: $v_{f}=n . f \rightarrow 5$ to 10 times,

- reduce cutting forces by more than $30 \%$,

- the possibility of machining parts geometrically complex shapes without vibration,

- the possibility of finishing (surface roughness is almost the same as in machining of pure), a constant shape and size (due to heat dissipation mostly chips).

The disadvantages, however, while the HSC are:

- with increasing cutting speed reduces the tool life,

- cutting materials and coatings must be adapted cutting parameters are not even known so optimal cutting parameters of HSC,

- for each component must be further developed a new strategy aside,

- HSC cannot be applied to conventional (older and less accurate) machine tools.

For optimum use of HSC technology must meet the following conditions.

Machine:

- machine have to work without vibration, 
- high stiffness,

- easier construction of moving parts,

- high spindle speed and minimum wobble,

- implementation of high feed motion (linear),

- armored guards (glass).

Cutting Tools:

- high precision clamping (wobble only 0.003 to $0.005 \mathrm{~mm}$ ),

- long shelf life, special geometry of the cutting, new coatings (CVD, PVD) e.g. TiAlN, TiAlCN, TiAlSiN (Humar, 2008),

- high precision balance (the method of clamping),

- high stiffness.

Workpiece:

- stability, vibration free clamping.

Tool clamping:

- High clamping accuracy,

- The high precision of clamping, hydraulic or heat (shrinkage), with cylindrical tools.

The cutting tool must be sufficiently rigid and accurate clamping (mills, drills, reamers, boring spindle). Clamping is done directly through the machine spindle to clamp the cutting edge (balance only $0.003 \mathrm{~mm}$ in length $\mathrm{x} 3 \mathrm{D}$ ), we can increase tool life and improve the quality of machined surfaces. In terms of accuracy are essential fixings and centrifugal forces. Therefore, the HSC should be very fine dynamic balance of cutting tool. HSC machining can be successfully implemented using new cutting materials and coating methods. Among the types of coated carbide include these types of supporting documents:

- Fine-grained cemented carbides (grain size of carbide $0.5 \div 0.8$ in diameter),

- ultra-fine grained cemented carbide (grain size of carbide $0.3 \div 0,5 \mathrm{~mm}$ ),

- cermets (TiN, TiC, TaC + metals $\mathrm{Ni}, \mathrm{Mo}$ ),

- cutting ceramics (CA, CM, CN, CC),

- $\quad$ synthetic very hard materials: PCBN (BN), PCD (DP).

\subsection{Qualitative aspects of dry machining}

The aim aside to dry (dry cutting), the elimination or minimization of the quantity used cutting fluid and thus reduce the cost of their purchase, maintenance and disposal and also to supporting acts such as: wet degreasing workpieces and chips, or spinning them. Process cost of cutting fluid are sometimes up to $17 \%$ of the total cost of machining operation.

From past experience aside and know that some machined materials using certain cutting materials is prepared in the dry without the use of cutting fluids (e.g. machining gray cast iron carbide tools, ISO - K10 to K40), respectively machining with cutting ceramics. For other machined materials are even recommended the use of cutting fluids in machining (magnesium, composites, laminates, PVC). The suitable cutting tool materials for dry machining are fine HW, HT, CC or BN, or DP. 
Widespread application of dry machining is becoming more hard machining hardened steel with a hardness of $45 \div 65 \mathrm{HRC}$. Among the machined materials that can be machined under drought include: aluminium and its alloys using diamondcoated $\mathrm{HC}$, respectively in the mass production car industry and using the tools of PKD (DP). Dry machining can be done only where there is no guarantee that the machine tool to achieve the same surface quality and mechanical piece that also time is the same as for cooling (Majerik \& Sandora, 2012).

\subsection{Aspects of hard machining technological process}

It is motivated by a desire to replace the finishing grinding hardened and hard materials, machining tool with defined geometry and the cutting tools for turning, boring, milling, but gradually and with reaming, drilling sporadically, respectively in planetary milling threading. This is a working material hardness of $45 \div 65 \mathrm{HRC}$ hardened steel, cemented and hardened steel, hardened cast iron, Ti - alloys, $\mathrm{Co}-$ alloy called stellite (Dubovska, Majerik \& Chochlikova, 2011).

Suitable hardness range of workpiece materials for hard machining is on Fig.1. Hard machining is classified as high-speed machining, although the cutting speed $\mathrm{v}_{\mathrm{c}}$ $=100$ to $150 \mathrm{~m} / \mathrm{min}$, cut in small cross sections ( $\mathrm{p}=0.15$ to $0.25 \mathrm{~mm}, \mathrm{f}=0.05$ to 0.2 $\mathrm{mm})$. Material removal rate is higher than in grinding time and reduces $-\mathrm{t}_{\mathrm{AS}}$. We can use cutting fluid, when apply mixed hard turning cutting ceramics $\left(\mathrm{Al}_{2} \mathrm{O}_{3}+\mathrm{TiC}\right)$ coated with waste, or the PCBN, as equivalent cutting materials for hard machining, and cooling may be also used.

Hard machining technology can be applied by the using a cutting materials, based on polycrystalline cubic boron nitride (BN), a mixed ceramic cutting $(\mathrm{CM})$, for helical milling of monolithic ultra-fine grain EN - ISO-K10/K20, coated with hard coatings. On figure 1 can see the extent of hardness of workpiece materials suitable for hard machining applications (Steiningerova \& Majerik, 2010).

\subsection{Aspects of combined machining process}

Current $\mathrm{NC}$ and $\mathrm{CNC}$ machine tools allow the combination of different methods and machining technology. For example the CNC lathe also can drill the holes in the axis and off-axis of workpiece, perpendicular to the axis milling area, flat and angular surfaces. (Majerik, Baska \& Danisova, 2009).

Progressive machining technology is a combination of turning and milling CNC machine, called turn-milling CNC machining centers, we can drill, mill, ream, bore or recess, even cutting internal threads planetary milling technology, using monolithic carbide cutters. (Dubovska et al., 2011).

Larger threads on CNC vertical milling carrousels do with circular cutter - a thorn with more exchange of cutting inserts which are coated by cemented carbide. (Majerik \& Jambor, 2011)

The picture at the opening cut edge planetary milling is shown in Fig. 2 and circular thread milling. Combination of milling and drilling is called plunge milling, or making large holes in the non-rotating workpiece. The gradually planetary milling 
in combination with drilling can see also on Fig. 2. Turn-milling in the manufacture of extruder screw can be seen in the application-level storage company - Fig. 3.

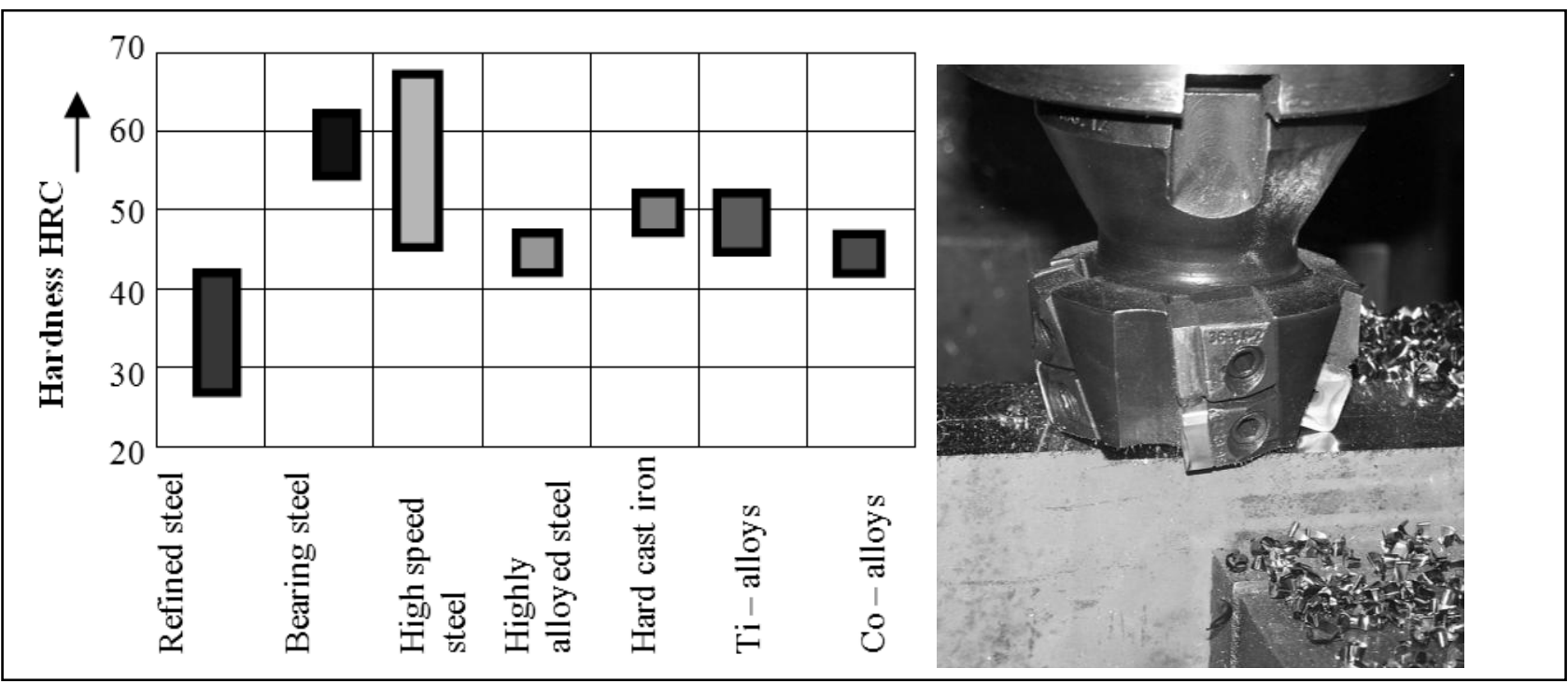

Fig. 1. HRC hardness of selected metallic materials - suitable for application of the hard machining technology and hard milling technological process of hardened abrasion resistant sheet Hardox 500 (Majerik \& Sandora, 2012)

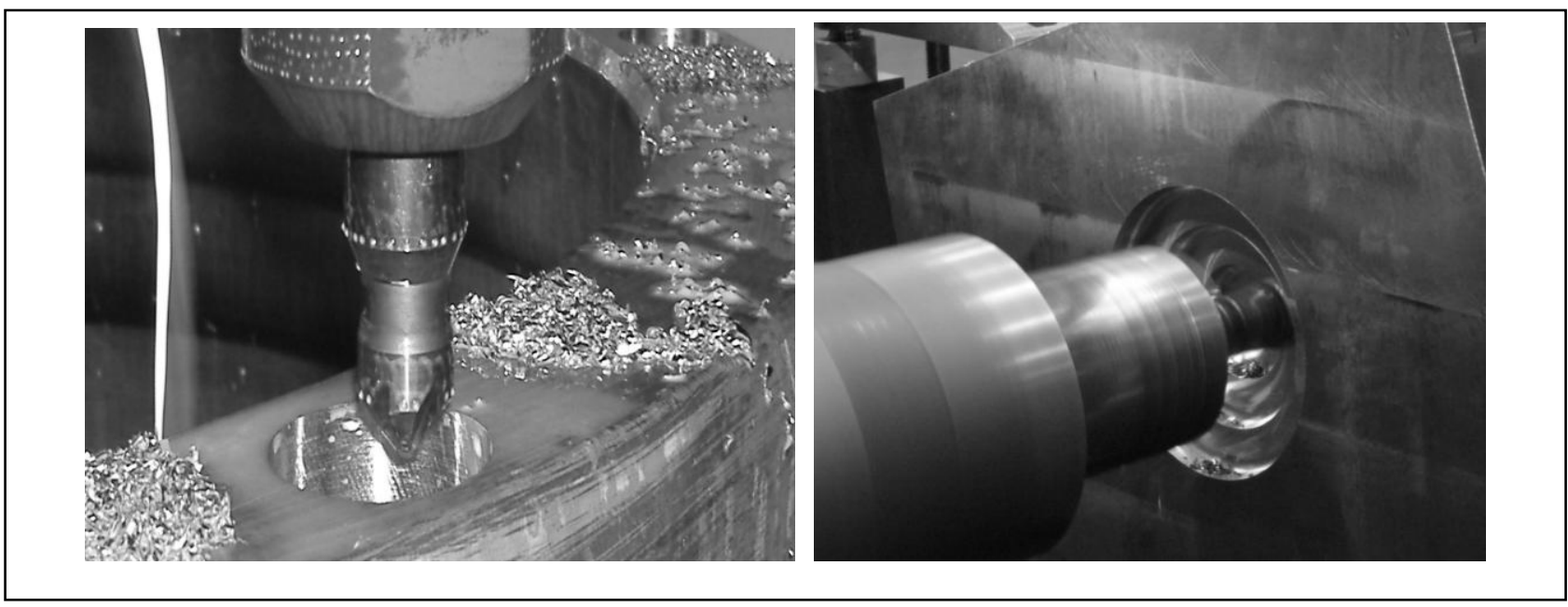

Fig. 2. Cut edge in the hole using a planetary milling technology, using circular interpolation motion with a gradual countersinking tool and planetary milling larger openings for more gradual transitions and drilling (Majerik \& Sandora, 2012)

\section{CAD/CAM system support for quality of production process}

The graphical tree dimensional CAD/CAM system CATIA V5R20 is one of the most used 3D graphical systems on the whole global world market. This graphical system belongs among the so-called higher class of all CAD/CAM systems. In addition to modelling and offers technical documentation and production of assembly (see fig 4), design and assembly areas of thin metal sheet profiles, different strength analysis, as well as simulate turning process, milling dies and moulds, drilling, threading technology etc (Majerik \& Jambor, 2011). 
The CATIA, which is the product of Dassault Systémes Co., are used mostly in medium or large technical companies. Creation of model components using CATIA V5R15 is implemented using the main Start menu, where modules are located, such as SKETCHER, which is creating 2D sketches and shapes, serving as a basis for the subsequent creation of 3D models in other parts of the product CATIA V5R20 (Part Design, Generative Shape Design, Sheet Metal Design, Wireframe and Surface Design, Weld Design).

Proper writing methodology was created, which would be able to define the ways between single devices during running process (Danisova et al., 2011).
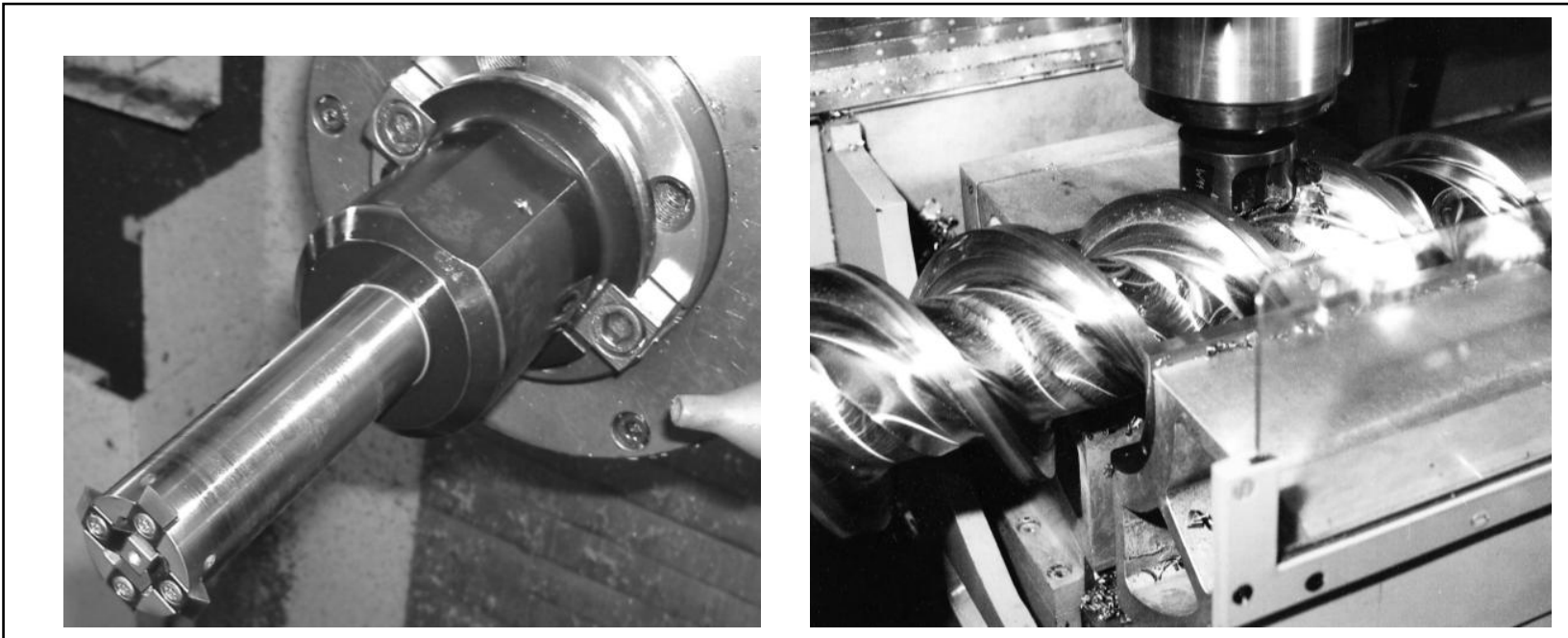

Fig. 3. Circular thread milling cutter Emuge Franken Gigantic and turn - milling technological application of the screw extruder (Majerik \& Sandora, 2012)

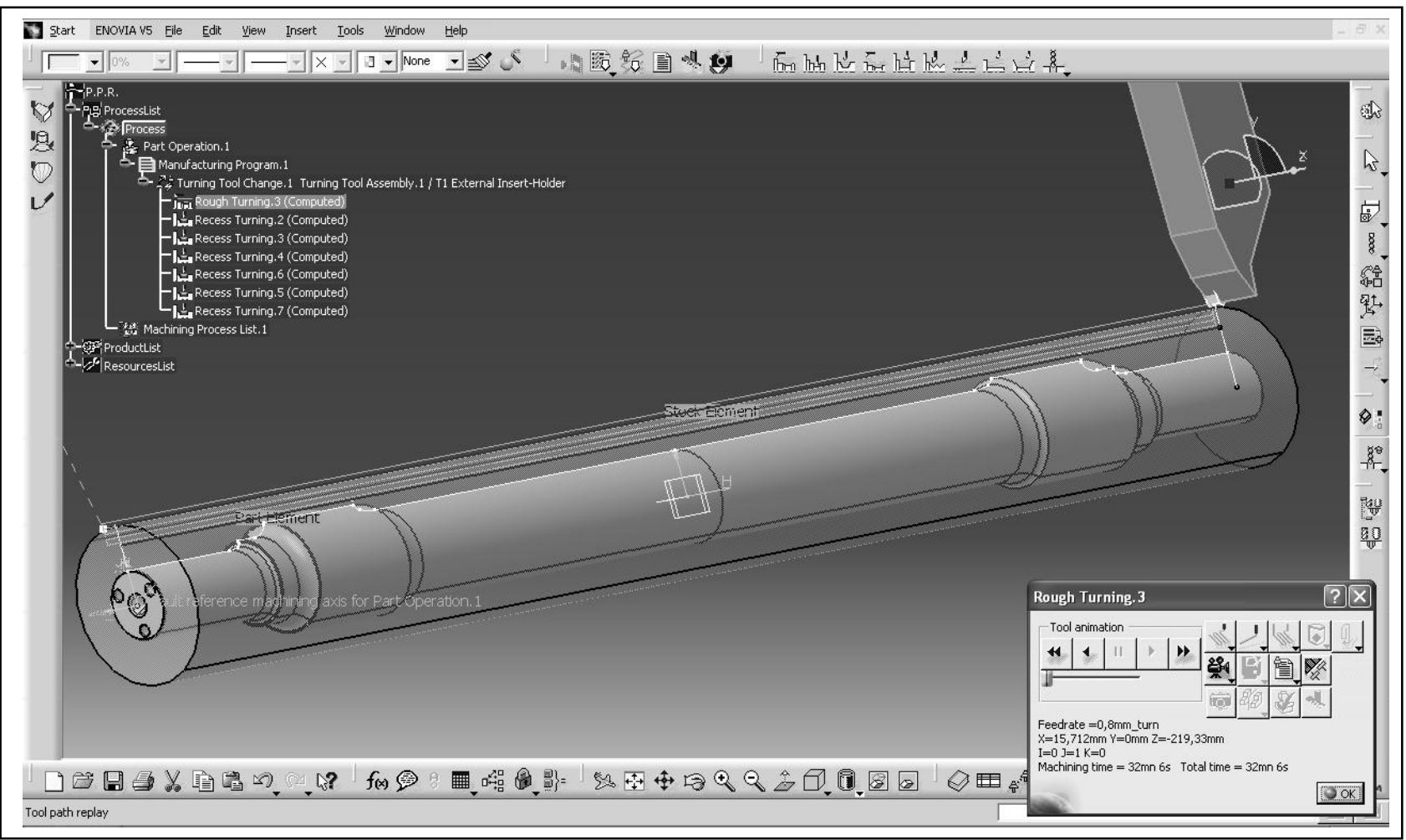

Fig. 4. The method of generating cutting tool paths (Majerik \& Jambor, 2011) 


\section{Jambor, J.: Quality of Production Process with CAD/CAM System Support}

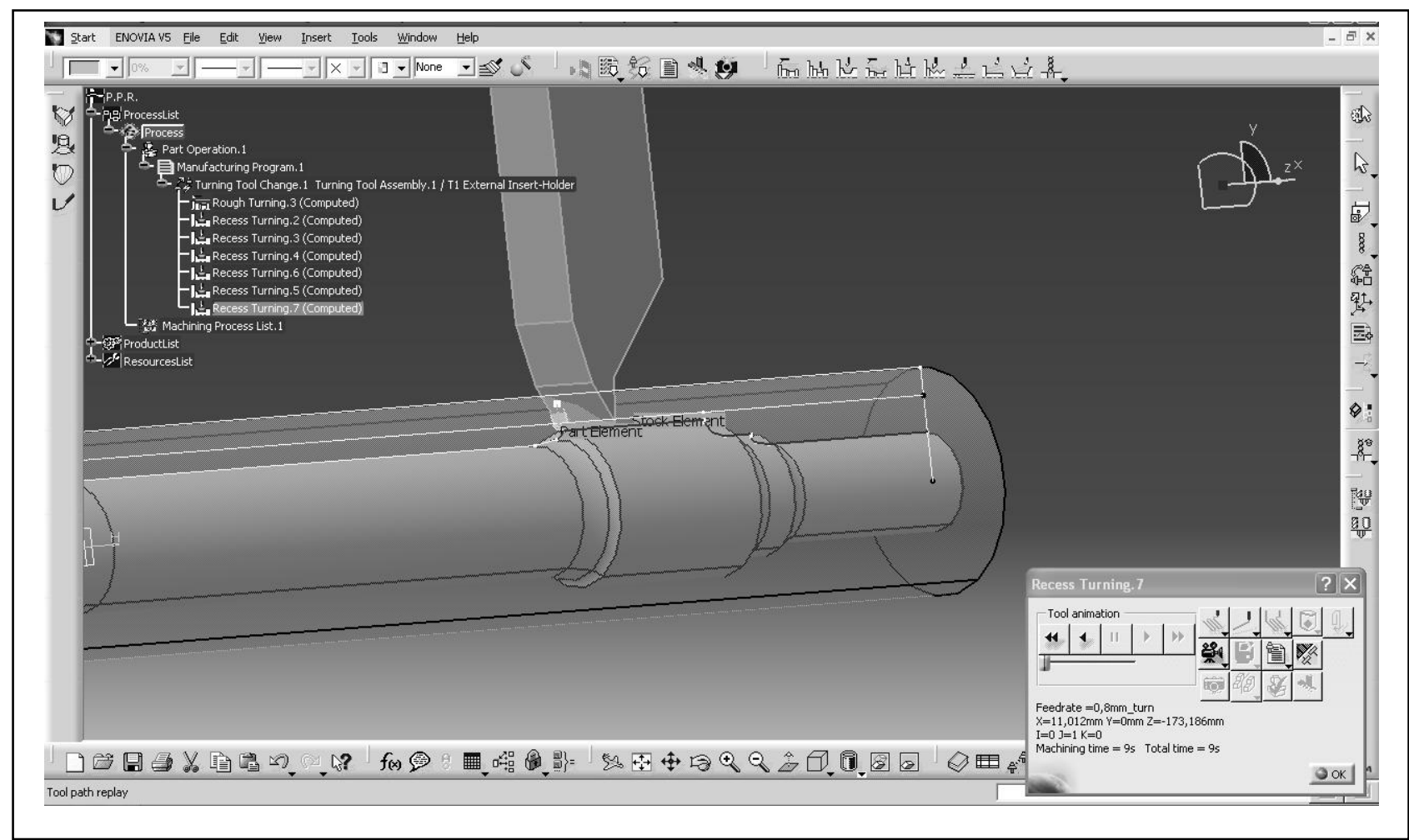

Fig. 5. Simulation of the machining process of the part in the section blank which is display and generating tool paths (Majerik \& Jambor, 2011)

In order to allow more complex the assembly and create precise technical drawings, it is important to know correctly draw models of machine parts, which form the basis for further work in the CAD/CAM systems. The advantage of modelling and the creation of the underlying sketches lies in the simplification of control, i.e. used all the features and icons are mostly single-level, creating a much better idea to work, unlike some other CAD systems. After creating a two dimensional sketch, it is possible through the function "Exit Workbench" to get into the 3D interface (PART DESIGN, SHAPE DESIGN, etc.). In 3D interface, then use the resulting functions will create PART or parts of the Product, works as if the module ASSEMBLY DESIGN. Advantage of CATIA is in its simplicity. Icons are placed directly on the sides of the active desktop, or you can activate them via the main menu View-Toolbars. This structure of the whole system is necessary, in view of the scope and job opportunities CATIA. Moreover, CATIA can do also conversion with the documentation created in older CAD systems (e.g. AutoCAD DWG format) directly in special module INTERACTIVE DRAFTING).

The creating procedure is clearly stated in the so-called working tree, which is always on the left side of the active desktop (see Fig. 5). Simulation of the machining process includes CATIA V5 NC Manufacturing module. The menu module is a 2axis, 2.5-axis, 3-axis, but even 5 axis machining and more. Through the following options can swing aside various rotating parts, but also milled grooves and drilled holes in the rotating parts, which may be particularly applicable if the machine tool contains the so-called management accessories C-axis. Milling of complex shapes can realize with main menu module offered by the $\mathrm{NC} 3$-axis and also 5-axis machining. The CAM module is designed to load a CAD model in CATIA with its 
own product tree, select either a blank from which the final piece will be made proposals for individual species, data on the movement of cutting tools and the rapid traverse movements and, if the correction tools machining, machining parameters to define and run a graphical simulation of the machining process. After defining the parameters needed CAM software generates data called CL (Cutter Location Data) that is a text entry in the ISO format that can be translated using the postprocessor.

\section{Conclusion}

Aim of this paper was on practical examples of HSC machining technology and programming $\mathrm{CNC}$ machines with $\mathrm{CAD} / \mathrm{CAM}$ system. CATIA indicate that relevance and coherence of the new technologies, materials, machinery, progressive methods and information tools that enable more efficient use of starting materials to produce a smaller costs. One objective of the article was to suggest the possibility of creating NC program production process components on a rotary chuck, or with minimal handling. This is achieved by shortening the time of the final machining while eliminating inaccuracies caused by manual switching of the workpiece. This paper presents a method of connecting HSC machining technology with the introduction of computer graphics contained in the CAD/CAM systems. CAM systems are used for preparing data and creating NC programs for manufacturing components. The first step in the simulation of the manufacturing process is the selection of appropriate shape and semi-finished parts. The choice of components was associated finding the material composition of parts and determining the class of its workability. Based on the findings of machinability were selected suitable cutting tools and cutting conditions for machining. The second step was to determine the production processes. A significant reduction in production time contributed use of a suitable preparation to facilitate the workpiece. The last processing step was measured and calculated results. Cutting conditions were established analytical calculations. We are based on empirical and theoretical relationship between cutting conditions. Manufacturing operations and instruments were chosen with respect to the geometry and the required precision assembly.

The results presented in this paper can be further exploited in the process of teaching courses and programming machines and technical practice for upgrading older solutions and processes of the main and additional times, while maintaining the dimensional accuracy of machine parts. Further research will be based CNC programming parts with complex shapes see links in the author of the modern CNC machines using modern types of cutting materials for machining. Just use modern CAE computer-aided systems such as CATIA leads to savings in time required by the programming of the machine design and manufacturing technology itself.

\section{Acknowledgements}

Our presented scientific paper was to connection between the theory and industrial practice. The practical applications were conducted in cooperation with the 
Jambor, J.: Quality of Production Process with CAD/CAM System Support

Dubnica Institute of technology DTI, along with industrial companies of the region of Trencin (e.g. MASH Integration Co. Trencin).

\section{References}

Danisova, N.; Sebenova, S. \& Velisek, K. (2011). Application of seguence diagram within tool change during machining, Annals of DAAAM for 2011\&Proceedings of the 22nd International World Symposium, pp. 04590460, ISSN 1726-9679, ISBN 978-3-901509-70-4, Austria Center Vienna, 2326th November 2011, Katalinic, B. (Ed.), Vienna, Austria

Dubovska, R.; Majerik, J.; Chochlikova, H. \& Baska, I. (2011). Residual stress measurement by $\mathrm{x}$-ray diffraction method, Annals of DAAAM for 2011\&Proceedings of the 22nd International World Symposium, pp. 13271328, ISSN 1726-9679, ISBN 978-3-901509-70-4, Austria Center Vienna, 2326th November 2011, Katalinic, B. (Ed.), Vienna, Austria

Dubovska, R.; Majerik, J. \& Chochlikova, H. (2011). Physico-chemical state Stabilization of high strength steels machined surface, Proceedings in manufacturing systems, Vol.6, No.4, (2011) p. 75-80, ISSN 2067-9238

Humar, A. (2008). Materials for cutting tools, MM publishing, ISBN 978-80-2542250-2, Prague, Czech republic

Jambor, J.; Majerik, J. (2009). Hard Die\&Mould Milling Process with CAD/CAM System Catia V5R18 Support, Annals of DAAAM for 2009\&Proceedings of the 20th International World Symposium, 25-28th November 2009, Austria center Vienna, ISSN 1726-9679, ISBN 978-3-901509-70-4, Katalinic, B. (Ed.), pp. 1465-1466, TUV, Vienna, Austria

Majerik, J.; Jambor, J. (2011). Prismatic milling simulation process and CNC programming in the CAD/CAM system CATIA V5R20, Annals of DAAAM for 2011\&Proceedings of the 22nd International World Symposium, pp. 06230624, ISSN 1726-9679, ISBN 978-3-901509-70-4, Austria Center Vienna, 2326th November 2011, Katalinic, B. (Ed.), Vienna, Austria

Majerik, J.; Baska, I. \& Danisova N. (2009). Automation \& simulation of the milling process with CAD/CAM support, AI Magazine, Vol.2, No.3, 2009, pp. 20-22

Majerik, J.; Jambor, J. (2010). Automation of hard turining process with Fanuc manual Guide-i support and CNC program generation, Proceedings in manufacturing systems, Vol.5, Special Number, (2010) p. 281-284, ISSN $1842-3183$

Majerik, J.; Jambor, J. (2011). Technological aspects of manufacturing process programming with CAD/CAM CATIA V5R20 support, Proceedings in manufacturing systems, Vol.6, Issue 4, (2011) p. 141-146, ISSN 1842-3183

Majerik, J.; Sandora, J. (2012). The new progressive cutting tools and machining technology methods, FST TnUAD, ISBN 978-80-8075-515-7, EAN 9788080755 157, Trencin, Slovakia

Steiningerova, J.; Majerik, J. (2010). Surface quality analysis of 102Cr6 bearing steel after CC6050 insert by hard turning and by SG grinding wheel, Proceedings in manufacturing systems, Vol.5, No.3, (2010) p. 137-142, ISSN 1842-3183, Bucharest, Romania 